\title{
IGF2 stimulates fetal growth in a sex- and organ-dependent manner
}

\author{
Veronica White ${ }^{1}$, Alicia Jawerbaum ${ }^{1}$, Maria Belen Mazzucco ${ }^{1}$, Martin Gauster ${ }^{3}$, Gernot Desoye ${ }^{2}$ and Ursula Hiden ${ }^{2}$
}

BACKGROUND: Insulin-like growth factor 2 (IGF2) is a key determinant of fetal growth, and the altered expression of IGF2 is implicated in fetal growth disorders and maternal metabolic derangements including gestational diabetes. Here we studied how increased levels of IGF2 in late pregnancy affect fetal growth.

METHODS: We employed a rat model of repeated intrafetal IGF2 administration in late pregnancy, i.e., during GD19-GD21, and measured the consequences on fetal organ weight and expression of insulin/IGF-axis components.

RESULTS: IGF2 treatment tended to increase fetal weight, but only weight increase of the fetal stomach reached significance $(+33 \pm 9 \% ; P<0.01)$. Sex-dependent data analysis revealed a sexual dimorphism of IGF2 action. In male fetuses, IGF2 administration significantly increased fetal weight (+13 $\pm 3 \%$; $P<0.05)$ and weight of fetal stomach $(+42 \pm 10 \% ; P<0.01)$, intestine $(+26 \pm 5 \% ; P<0.05)$, liver $(+13 \pm 4 \% ; P<0.05)$, and pancreas $(+25 \pm 8 \% ; P<0.05)$. Weights of heart, lungs, and kidneys were unchanged. In female fetuses, IGF2 increased only stomach weight $(+26 \pm 9 \%$; $P<0.05)$. Furthermore, gene expression of insulin/IGF axis in the heart, lungs, liver, and stomach was more sensitive toward IGF2 treatment in male than in female fetuses.

CONCLUSION: Data suggest that elevated circulating IGF2 in late pregnancy predominantly stimulates organ growth of the digestive system, and male fetuses are more susceptible toward the IGF2 effects than female fetuses.

$\mathbf{F}$ etal growth is crucially determined by a group of peptides/ proteins of the insulin/insulin-like growth factor (IGF) axis comprising IGF1 and IGF2, insulin, their receptors, and their binding proteins, which bind IGF1 and 2 and modulate their action. The central role of IGFs and insulin in fetal growth was shown by a multitude of studies in human and animals (1). IGF1 regulates size prenatally, reflected by the correlation of cord blood IGF1 with fetal size, and determines postnatal growth until adolescence (2). In contrast to this, IGF2 is a growth factor particularly important for fetal growth (3) and does not regulate body length later on. IGF2 is synthesized by various fetal tissues and organs, in particular by the fetal pancreas (4) and liver (5). The growth-promoting action of IGF2 is mediated by IGF1-receptor and the insulin receptor $(6,7)$. The role of the IGF2-receptor in growthpromoting effects of IGF2 is controversial, as it was shown to function as both a signaling and a clearance receptor for IGF2 (ref. 8). Thus, potential receptors for IGF2 are present on virtually all fetal organs, but at different levels. Bioavailability of IGF2 is further modified by circulating as well as locally acting IGF-binding proteins (9).

IGF2 is transcriptionally regulated by the non-coding RNA H19 and both are imprinted in human and rodents, indicating the key role of IGF2 in fetal development. Thus, the levels of IGF2 as well as of $H 19$ are modulated by DNA methylation. Whereas IGF2 is maternally imprinted and paternally expressed, $\mathrm{H} 19$ is expressed only from the maternal allele (10). Disruption of genomic imprinting of H19/IGF2 genes results in two clinical syndromes with opposite growth phenotypes: loss of maternal imprinting of IGF2 underlies the Beckwith-Wiedemann syndrome (BWS) and is characterized by fetal overgrowth (11). Loss of paternal imprinting of H19 is common to Silver-Russell syndrome characterized by fetal growth retardation (11).

Changes in IGF2 levels are associated with extremes of fetal weight, such as fetal growth restriction $(12,13)$. DNA methylation at the IGF2/H19 locus is a key determinant of the newborn's weight variance within normal range (14). Moreover, fetal IGF2 levels may be modulated by environmental insults, including nutrition (15) and maternal metabolism: maternal gestational diabetes (GDM) is a glucose intolerance that clinically manifests mainly in the second half of pregnancy. It is associated with elevated fetal cord blood IGF2 levels (16), which correlate with altered methylation of the IGF2/H19 locus (16). In fact, GDM fetuses are heavier than fetuses from uncomplicated pregnancies (17).

Here we aimed to investigate the effect of elevated fetal IGF2 in late pregnancy and which particular fetal organs are target of IGF2 growth-promoting effects. To this end, we used a rat model of intrafetal administration and investigated the

\footnotetext{
'Laboratory of Reproduction and Metabolism, Center for Pharmacological and Botanical Studies, CEFyBO-CONICET, School of Medicine, University of Buenos Aires, Buenos Aires, Argentina; ${ }^{2}$ Department of Obstetrics and Gynaecology, Medical University of Graz, Graz, Austria; ${ }^{3}$ Institute of Cell Biology, Histology and Embryology, Medical University of Graz, Graz, Austria. Correspondence: Ursula Hiden (ursula.hiden@medunigraz.at)

Received 2 March 2017; accepted 31 August 2017; advance online publication 18 October 2017. doi:10.1038/pr.2017.221
} 


\section{Articles White et al.}

effect of increased IGF2 levels on fetal organ weight and gene expression of insulin/IGF-axis components in late pregnancy.

\section{METHODS}

\section{Animals}

Albino Wistar rats were bred with free access to commercial rat chow (Asociación Cooperativa Argentina, Buenos Aires, Argentina) and tap water. The animals were kept at a controlled temperature of $20^{\circ} \mathrm{C}$, with $14 \mathrm{~h}$ light and $10 \mathrm{~h}$ dark lighting cycles. The guidelines for the care and use of animals approved by the local institution were followed, according to the Principles of Laboratory Animal Care (NIH publication number 85-23, revised 1985, http://grants1.nih. gov/grants/olaw/references/phspol.htm).

\section{Experimental Design}

Female Albino Wistar rats at 12 weeks of age were mated with males. The presence of sperm cells in vaginal smears confirmed the pregnant state (day 1 of pregnancy).

\section{IGF2 Administration to Fetuses and Sample Collection}

On day 19 of gestation, mothers were shortly anesthetized in a $\mathrm{CO}_{2}$ chamber, followed by slight vapors of ether. An abdominal incision was performed and the left horn of the uterus was exposed. Rats with five to seven fetuses in each uterine horn were used. The fetuses were numbered from the ovary and alternatively injected subcutaneously on their backs through the uterine wall with $50 \mu \mathrm{l}$ of either saline or human recombinant IGF2 $20 \mathrm{nmol} /$ fetus (Gentaur, Germany). Human IGF2 was chosen, as it is highly homologous to rat IGF2 and induces growth-promoting effects in rats (18). After administration, the left uterine horn was carefully introduced in the abdominal cavity, and the abdominal muscle layer and the skin layer were independently sewn. The entire surgery lasted less than $10 \mathrm{~min}$. The animals were completely recovered after $15 \mathrm{~min}$. The procedure was repeated on days 20 and 21 of gestation. After $3 \mathrm{~h}$ of the injection on the last day, the mothers were slightly anesthetized in a $\mathrm{CO}_{2}$ chamber and the animals killed by cervical dislocation. The fetuses from the left horn were immediately removed and killed by decapitation, and fetal blood was collected in heparinized tubes. Fetal plasma was obtained by blood centrifugation, and was conserved at $-80{ }^{\circ} \mathrm{C}$ for further determinations. The sex of the fetuses was recorded and their organs carefully removed under a stereomicroscope using microsurgical dissecting. Fetuses and fetal organs were weighed, stored in RNAlater, and kept at $-20^{\circ} \mathrm{C}$ for future analysis. Weight of the non-injected fetuses from the right uterine horn was also recorded $(3.10 \pm 0.08 \mathrm{~g})$ and was similar to that of the salineinjected fetuses form the left horn.

Overall, a total of 13 dams were subjected to the procedure. Only litters containing at least one male and one female saline-treated fetus, and one male and one female IGF2-treated fetus, were used $(n=10)$. One fetus of each group was selected for further analysis, yielding a total of 40 fetuses. Of these fetuses, fetal weight and organ weight were recorded, and plasma was preserved for enzyme-linked immunosorbent assay (ELISA). Moreover, of each of these four groups, five to eight organ samples were randomly chosen for mRNA analysis.

\section{Validation of the Method}

Previously, we have already successfully used the method of intrafetal administration of substances at the term of gestation $(19,20)$. In order to ascertain complete distribution of the IGF2 over all fetal organs, we performed the same procedure with a blue dye (Evans Blue, $5 \%$ in phosphate-buffered saline) instead of IGF2. Similar to the IGF2 administration, the mothers were killed $3 \mathrm{~h}$ after injection on day 21, and fetuses were collected. The dye was homogenously distributed over all fetal organs (Supplementary Figure S1 online). We also assessed five different IGF2 concentrations $(2,000,200,20,2$, and $0.2 \mathrm{nmol} /$ fetus /day) and choose the minimal concentration that induced an increase in IGF2 plasma concentrations with least lethality. The highest concentration induced an increase (30\%) in fetal lethality. The survival of the fetuses injected with the concentration chosen (20 nmol/fetus/day) showed no change in survival compared with the saline-injected ones (saline: 93\%, IGF2: $94 \%)$. Measurement of human in fetal plasma depicted no signal for saline-treated fetuses and $11.2 \pm 1.0 \mathrm{ng} / \mathrm{ml}$ in the IGF2administered ones.

\section{IGF2 Measurement in Fetal Plasma}

Human IGF2 was measured in fetal plasma using a commercial EIA kit (Diagnosmed, Buenos Aires, Argentina). Sample-free IGF2 concentration was obtained from the calibrator curve. Intra- and interassay coefficients of variation were $6.4 \%$ and $10.5 \%$, respectively.

For the measurement of endogenous free circulating Igf2 levels in the fetal plasma, we developed an ELISA (Duoset Mouse IGF 2 ELISA Development) that was as equally sensitive for mouse and rat Igf2 according to the manufacturer's instructions (R\&D Systems, Abingdon, UK) as described previously (21).

\section{Real-Time Quantitative PCR}

cDNA was synthesized incubating $1 \mu \mathrm{g}$ of extracted total RNA in a first-strand buffer containing $200 \mathrm{U}$ of MMLV enzyme (Promega, Sunnyvale, CA), $7.5 \mathrm{mM}$ of random primer hexamers (Promega), and $0.5 \mathrm{mM}$ of each dNTP (Invitrogen, Carlsbad CA). The reaction mix was incubated at $37^{\circ} \mathrm{C}$ for $45 \mathrm{~min}$, followed by $15 \mathrm{~min}$ at $45^{\circ} \mathrm{C}$ and $20 \mathrm{~min}$ at $70^{\circ} \mathrm{C}$.

Gene expression assays for Rpl30 (Rn00321148_g1), Igf1 (Rn99999087_m1), Igf2 (Rn01454518_m1), Igf1r (Rn01477918_m1), Igf2r (Rn01636937_m1), Insr (Rn01637243_m1), Igfbp1 (Rn01452798_m1), Igfbp2 (Rn00565473_m1), and Igfbp3 (Rn01401281_m1), and the TaqMan Universal Master mix II were purchased from Applied Biosystems (Carlsbad, CA) and the methodology followed according to the manufacturer's instructions. The $\mathrm{ABI}$ Prism 7900 Sequence Detection System (Applied Biosystems) PCRcycling conditions were as follows: initial denaturation at $95^{\circ} \mathrm{C}$ for $10 \mathrm{~min}$, followed by 40 cycles at $94^{\circ} \mathrm{C}$ for $30 \mathrm{~s}, 60^{\circ} \mathrm{C}$ for $15 \mathrm{~s}$, and $72{ }^{\circ} \mathrm{C}$ for $30 \mathrm{~s}$, and a 10 -min terminal incubation at $72^{\circ} \mathrm{C}$. Sequence Detector Software (SDS version 1.6.3; Applied Biosystems) was used to extract the PCR data, and threshold lines were chosen automatically. Rpl30 expression was used as an internal expression control because it did not vary between groups. Data were analyzed using the $2^{-\Delta \Delta \mathrm{Ct}}$ method.

\section{Heat Map}

Expression data from real-time quantitative PCR were used to generate a heat map. To this end, $\Delta \Delta \mathrm{Ct}$ values for each gene in each organ were calculated using the mean of the $\Delta \mathrm{Ct}$ values of male and female control fetuses. The mean values for male and female fetuses were used to construct the heat map in MS Excel. Low $\Delta \Delta \mathrm{Ct}$ values indicating high mRNA expression were illustrated in black, high $\Delta \Delta \mathrm{Ct}$ values indicating that low mRNA expression were illustrated in white.

\section{Statistical Analysis}

Relative differences between samples were analyzed by Student's $t$ test or by ANOVA with Bonferroni's post hoc test. Differences were considered statistically significant with a $P$ value of $<0.05$. Male and female fetuses administered with saline or IGF2 from a total of 10 rats were included in the statistical analysis. Rats with five to seven fetuses in each horn were included and rats with fetal lethality were excluded.

\section{RESULTS}

In order to analyze the effect of IGF2 on fetal organs in late pregnancy, we administered human recombinant IGF2 to rat fetuses during the last 3 days of gestation. As a control that substances administered in such a way in fact reach the fetal organs, we monitored the transport of Evans Blue, a blue dye 


\section{IGF2 alters fetal growth sex-dependently Articles}

that was injected following the same protocol. After the last administration of Evans Blue at GD21, we observed blue staining in all organs investigated, confirming the distribution of the dye into the organs after the procedure (Supplementary Figure S1 online). Furthermore, we measured circulating IGF2 levels in fetal plasma after the last administration of IGF2. The EIA is specific for human, but not for rat IGF2. Only in the plasma of IGF2-administered fetuses we measured IGF2 levels $(11.2 \pm 1.0 \mathrm{ng} / \mathrm{ml})$, whereas no IGF2 was detected in the saline-administered fetuses, confirming that the injected IGF2 reached the fetal circulation. As a response to exogenous IGF2 injection, endogenous circulating rat Igf2 decreased in the injected group from $303 \pm 26$ to $82 \pm 22 \mathrm{pg} / \mathrm{ml}$.

\section{Effect of IGF2 on Fetal Organ Weight}

The weight of IGF2-treated fetuses tended to be higher than the controls $(P=0.09)$. In addition, intestines from IGF2administered fetuses presented a tendency to be heavier than the intestines from the saline-injected fetuses $(P=0.05)$. Furthermore, intrafetal administration of IGF2 induced a clear increase in fetal stomach weight $(P<0.01)$. However, fetal hearts, lungs, kidneys, and pancreas displayed no changes in weight compared with the organs from salineinjected fetuses (Table 1).

\section{Effect of IGF2 on Expression of Fetal Insulin/IGF-Axis Genes} Gene expression of IGF-axis components, i.e., Igf1, Igf2, Igflr, $I g f 2 r$, Insr, Igfbp 1, Igfbp2, and Igfbp3, was measured in the following four fetal organs: heart, lungs, liver, and stomach. These organs were chosen as particularly sensitive toward IGF2 treatment; as the liver is a key organ for IGF2 production, fetal lung development is regulated by IGF2 (22), and heart development is sensitive toward loss of IGF2 imprinting in BWS (23). As stomach weight revealed the strongest change in IGF2-injected fetuses, stomach was also included. Although the expression of insulin/IGF-axis genes was unchanged in fetal hearts, IGF2 treatment induced changes in lungs, liver, and stomach (Table 2).

Table 1. Weight of saline (control) or IGF2-treated fetuses and fetal organs on day 21

\begin{tabular}{lccc}
\hline & Controls & IGF2 & Significance \\
\hline Fetus (g) & $3.00 \pm 0.10$ & $3.28 \pm 0.12$ & $P=0.09$ \\
Heart (mg) & $17.8 \pm 1.2$ & $18.2 \pm 1.0$ & n.s. \\
Lungs (mg) & $72.2 \pm 3.2$ & $71.2 \pm 2.0$ & n.s. \\
Kidneys (mg) & $18.1 \pm 1.0$ & $19.9 \pm 0.9$ & n.s. \\
Liver (mg) & $202.0 \pm 9.5$ & $223.5 \pm 8.0$ & n.s. \\
Stom/ach (mg) & $22.6 \pm 1.5$ & $30.2 \pm 2.1$ & $P<0.01$ \\
Intestine (mg) & $62.0 \pm 3.5$ & $73.0 \pm 4.0$ & $P=0.05$ \\
Pancreas (mg) & $16.2 \pm 1.2$ & $19.6 \pm 1.6$ & n.s. \\
\hline
\end{tabular}

IGF2, Insulin-like growth factor 2; n.s., not significant.

Data are given as mean \pm SEM. $n=20$ fetuses (male/female: 10/10) for all organs

from 14 different mothers.
Table 2. Changes in gene expression of insulin/IGF axis in organs between saline and IGF2-treated fetuses

\begin{tabular}{lccll}
\hline & Heart & Lungs & Liver & Stomach \\
\hline lgf1 & $1.5 \pm 0.2$ & $0.7 \pm 0.3$ & $4.0 \pm 0.5^{*}$ & $1.7 \pm 0.5$ \\
Igf2 & $1.0 \pm 0.2$ & $0.7 \pm 0.5$ & $1.4 \pm 0.6$ & $0.9 \pm 0.2$ \\
Igf1r & $0.8 \pm 0.4$ & $13.0 \pm 0.8^{* *}$ & $7.0 \pm 0.6^{* *}$ & $2.3 \pm 0.5^{*}$ \\
Igf2r & $0.9 \pm 0.2$ & $0.2 \pm 0.6^{*}$ & $1.6 \pm 0.4$ & $1.3 \pm 0.6$ \\
Insr & $1.1 \pm 0.5$ & $0.6 \pm 0.5$ & $6.2 \pm 0.7^{*}$ & $1.0 \pm 0.2$ \\
Igfbp1 & $0.7 \pm 0.4$ & $7.0 \pm 0.7^{*}$ & $1.3 \pm 0.5$ & $1.2 \pm 0.4$ \\
lgfbp2 & $0.6 \pm 0.4$ & $1.2 \pm 0.4$ & $1.1 \pm 0.7$ & $1.5 \pm 0.6$ \\
lgfbp3 & $0.8 \pm 0.2$ & $1.6 \pm 0.6$ & $1.6 \pm 0.5$ & $2.2 \pm 0.3^{*}$ \\
\hline
\end{tabular}

IGF2, Insulin-like growth factor 2.

Data are given as fold change vs. control \pm SEM. $n$ (heart) $=6 / 6, n$ (lungs) $=5 / 5, n$ (liver) $=10 / 10, n$ (stomach) $=6 / 7$ control/IGF2-treated fetuses.

${ }^{*} P<0.05$; ${ }^{*} P<0.01$.

\section{Sex-Dependent Changes in the Effect of Fetal Administration of} IGF2

The IGF system is sexually dimorphic in rats and human $(24,25)$. Therefore, we furthermore stratified the analyses for fetal sex.

Sex-Dependent Effects of IGF2 on Fetal and Fetal Organ Weight Within the saline-treated fetuses we observed no sexdependent differences in weight of fetuses and fetal organs. Surprisingly, administration of IGF2 increased fetal weight only in male fetuses $(P<0.05)$, whereas weight of female fetuses was unchanged by IGF2 treatment. Furthermore, in female fetuses, weights of heart, lungs, and kidneys were unaltered by IGF2, and only stomach weight was increased $(P<0.05)$. By contrast, male fetuses evinced a general response in organ weight due to the IGF2 administration: Weights of male fetal liver, intestine, stomach, and pancreas were increased $(P<0.05$; Figure 1).

\section{Circulating Levels of IGF2}

In order to ensure that IGF2 levels were similar in male and female fetuses, we quantified circulating IGF2 dependent on fetal sex. Its levels were similar in male $(11.3 \pm 1.3 \mathrm{ng} / \mathrm{ml})$ and female $(11.0 \pm 1.6 \mathrm{ng} / \mathrm{ml})$ fetuses.

\section{Sex-Dependent IGF2 effects on the Fetal Insulin/IGF Axis}

A heat map was generated to illustrate changes in gene expression between male and female control and IGF2administered fetuses. Basal gene expression levels of the insulin/IGF-axis components in the heart, lungs, liver, and stomach were higher in female than in male fetuses; however, IGF2 administration resulted in more profound changes in male than in female fetuses (Figure 2).

\section{Fetal Liver Responds in a Sex-Dependent Manner to IGF2 Administration}

The liver is a central organ for IGF production, and it was also among the organs in which IGF2-dependent weight gain differed between male vs. female fetuses. Therefore, we 
a

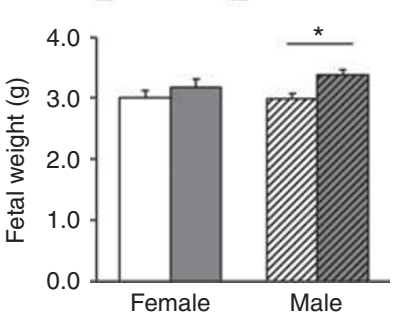

e

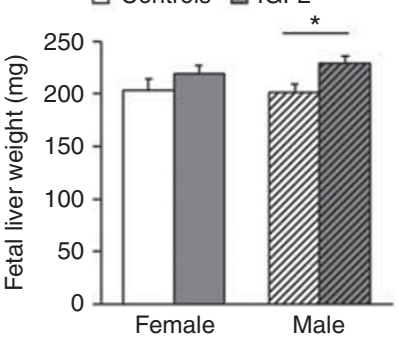

b

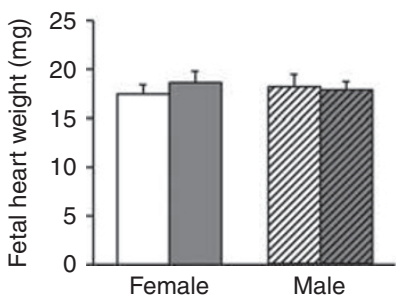

f

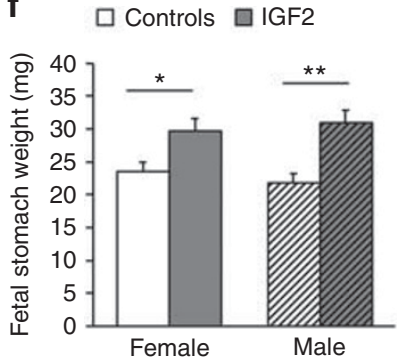

C $\square$ Controls $\square$ IGF2

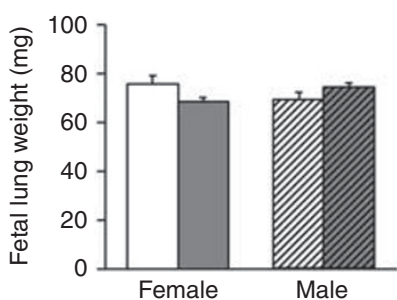

g

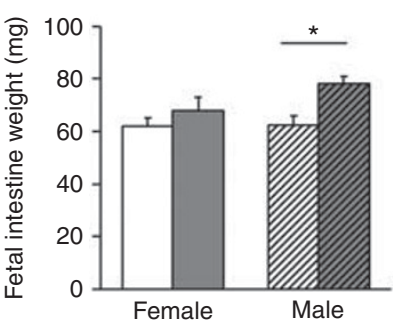

d

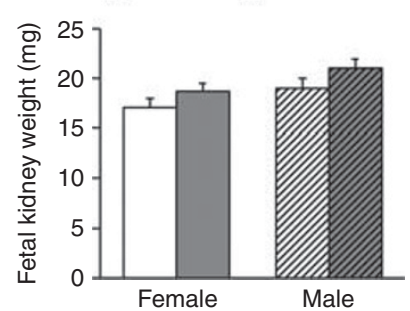

h

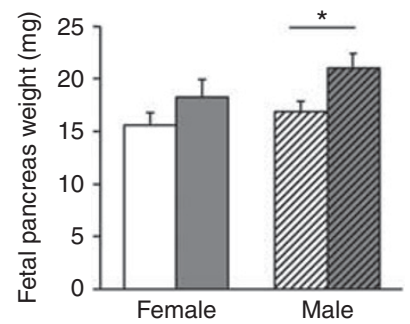

Figure 1. Fetal weight and weights of fetal organs from female (open bars) and male fetuses (striped bars) injected with saline (white bars) or IGF2 (grey bars). (a) Fetal weight. (b) Fetal heart weight. (c) Fetal lungs weight. (d) Fetal kidney weight. (e) Fetal liver weight. (f) Fetal stomach weight. (g) Fetal intestine weight. (h) Fetal pancreas weight. Each bar represents the mean \pm SEM from 10 fetuses from 10 different mothers. Statistical test: twoway ANOVA, post-test Bonferroni, ${ }^{*} P<0.05,{ }^{* *} P<0.01$.

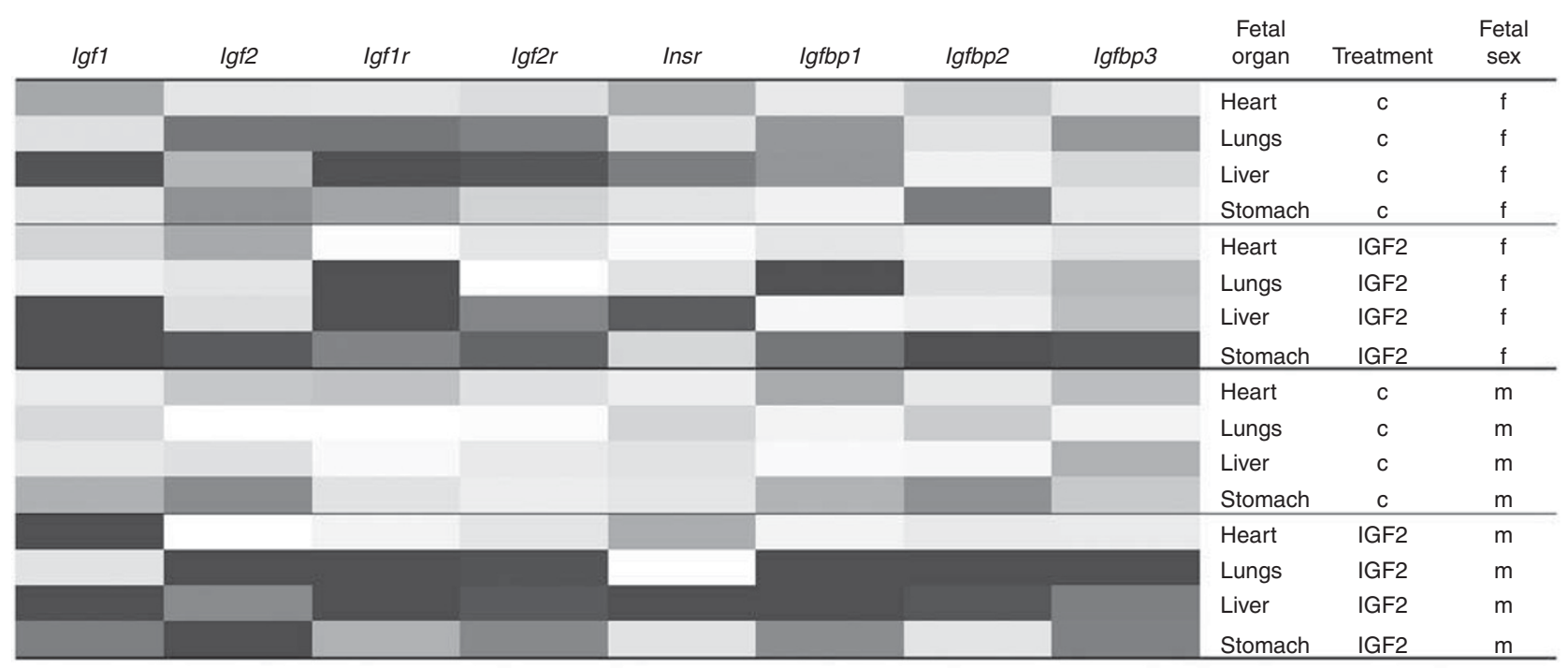

Figure 2. Heat map depicting the mean organ-specific gene expression of each component of the insulin/IGF axis in male and female fetuses administered with saline, and in male and female fetuses injected with IGF2. Black indicates high gene expression and white indicates low gene expression. c, saline-treated control fetuses; IGF2, IGF2-treated fetuses; f, female fetuses; $\mathrm{m}$, male fetuses. $n$ numbers are given for male and female (m/f) fetuses separately. $n$ (heart): c = 6 (3/3), IGF2 = 5 (3/2); $n$ (lungs): c = 5 (2/3), IGF2 = 5 (1/4); $n$ (liver): $c=8$ (3/5), IGF2 = 7 (4/3); $n$ (stomach): $c=6$ (3/4), IGF2 = 7 (4/3).

assessed the expression of the insulin/IGF-axis components in the liver in a sex-dependent manner. Sex-independent analysis showed that gene expression of Igf1, Igf1r, and Insr was upregulated in the livers from both male and female IGF2-administered fetuses (Table 2). However, when analyzed separately for both sexes, only livers from male fetuses responded to IGF2 injection with increased expression of $I g f 1, I g f 1 r$, and Ins $r$, whereas in livers of female fetuses the IGF2 effect was not significant (Figure 3).

\section{DISCUSSION}

We investigated organ-specific endocrine effects of IGF2 in late pregnancy on fetal weight, fetal organ growth, and gene expression of the insulin/IGF axis. Our main finding was that male fetuses were more susceptible toward IGF2 effects than female fetuses. For instance, growth was stimulated predominantly in male fetuses, and also the expression of insulin/IGF-axis genes was particularly modulated in male organs. 


\section{IGF2 alters fetal growth sex-dependently $\quad$ Articles}

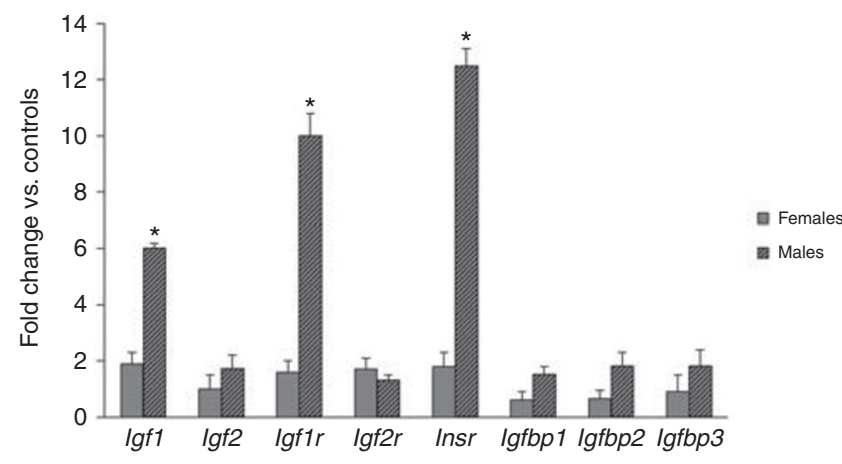

Figure 3. Sex dependent mRNA expression of insulin/IGF-axis components in the liver from IGF2-administered male and female fetuses compared with saline-injected ones. Data are expressed as fold change (mean $\pm \mathrm{SEM}$ ) in IGF2-treated fetuses relative to controls $(=1)$ for each target gene. Females: open bars ( $n=5 / 3$ control/IGF2-treated fetuses), males: gray bars ( $n=3 / 4$ control/IGF2-treated fetuses) with each fetus deriving from a different mother. Statistical test: Student's $t$-test, ${ }^{*} P<0.05$ vs. the respective saline-treated controls of the same sex.

The effect of increased IGF2 levels in embryonic and fetal mammalian development was observed and investigated in two different situations: the loss of IGF2 imprinting in BWS in humans as well as the overexpression of $I g f 2$ in rodents. Both cause elevated IGF2 expression throughout the entire period of intrauterine development. BWS as well as Igf2 overexpression result in fetal overgrowth $(26,27)$. Igf2 overexpression in rodents stimulates embryonic and fetal growth (27-29), with the growth-promoting effect of IGF2 being more evident at term gestation (28).

In contrast to this, we investigated the growth-promoting effect of IGF2 levels that were elevated only during late pregnancy. Similar to situations of increased IGF2 during the entire period of fetal development, we also observed a trend to increased fetal weight. Surprisingly, the growth-promoting effect was dependent on fetal sex. When male and female fetuses were analyzed separately, the IGF2-induced fetal weight gain was observed predominantly in the males.

Such a sex-dependent effect of IGF2 on fetal growth was not reported previously. However, a sexual dimorphism exists in the IGF system in human and rodents with higher levels of IGF1 and IGF-binding protein 3 in female cord blood (24), and in females postnatally (25). This sexual dimorphism in the IGF system may contribute to the observation that growth of male fetuses seems more susceptible toward environmental influences, such as nutrient supply and metabolic and hormonal derangements: Male fetuses are more likely to be macrosomic in normal pregnancy (30) and in pregnancies complicated by maternal GDM (31), where the risk for macrosomia becomes even higher (32). At the other extreme of metabolic and nutritional derangements, also maternal undernutrition was shown to affect male fetuses more than female fetuses. In mice, maternal low-protein diet during the pre-implantation period reduces fetal liver expression of $I g f 2$ only in male fetuses (33).
Analysis of the effect of elevated IGF2 in late pregnancy on fetal organ weight revealed that not all organs responded to the growth-promoting effect of IGF2. Most susceptible toward the IGF2 treatment were organs of the digestive system, i.e., stomach and, by trend, the intestine. When organ weight was analyzed depending on fetal sex, this observation became even more obvious for the male fetuses with the stomach, intestine, liver, and pancreas being heavier in the IGF2-treated group. A role of IGF2 in the growth of digestive organs may indicate that IGF2 predisposes the fetus for a nutrient-rich environment. Overgrowth of the digestive system in a situation of excess nutrient supply may seem counterintuitive as it ultimately may promote overgrowth and adiposity. However, such effects resemble other established mal-programming effects resulting from excess nutrient supply, such as an increased risk for obesity and diabetes of offspring of obese or diabetic mothers $(34,35)$. In addition, BWS can be associated with organomegaly of several organs such as the liver, kidneys, spleen, pancreas, and heart (26). However, features of BWS are very variable. Besides, the phenotype of BWS is a product of disturbed genomic imprinting in the chromosomal region 11p15 and thus affects also other genes, such as the cell cycle regulator CDKN1C (cyclin-dependent kinase inhibitor 1C) and the non-coding RNAs KCNQ1OT1 and H19 (ref. 11). Similar to BWS, different approaches to increase Igf2 action in rodents, either by overexpression, or reducing Igf2r levels, report hypertrophy the fetal heart, liver, or kidneys $(27,28,36)$. A study focussing particularly on the effect of Igf2 overexpression on the fetal intestine reported an increased crypt length in the small intestinal and the risk for intestinal adenomas (37). Moreover, it has been observed that transgenic overexpression of Igf2 in mice induces pancreatic cell hyperplasia (38). Deletion of the H19 locus in mice and the consequent increase in Igf2 resulted in placental overgrowth (39). Differences to our model with weight gain predominantly in the male fetuses and unaffected fetal hearts and kidneys may be related to the fact that we applied IGF2 only in late pregnancy, and that other studies did not determine organ growth in relation to fetal sex.

GDM is a pregnancy pathology that manifests in the second half of gestation and is, among other metabolic derangements, associated with elevated fetal IGF2 levels. In fact, fetuses exposed to maternal GDM display an increase in liver length $(40,41)$. As GDM is not only associated with increased IGF2 but also with derangements of insulin and other hormones, cytokines, and growth factors (42), the specific role of IGF2 is impossible to interpolate. Moreover, to the best of our knowledge, fetal organ development in response to maternal diabetes in human was not yet analyzed depending on fetal sex.

For the analysis of insulin/IGF-axis gene expression, we focussed on the fetal heart, lungs, liver, and stomach. Changes in gene expression did not always parallel changes in weight. Thus, fetal lungs did not respond to IGF2 treatment with weight increase, but with an increase in gene expression of $I g f 1 r$, Igfbpl, and a decrease in the $I g f 2 r$, of which the protein 


\section{Articles | White et al.}

contributes to IGF2 clearance. Overall, data revealed that, in control fetuses, insulin/IGF-axis genes were expressed to a higher extent in the female organs. However, after IGF2 administration, male fetuses responded with an increase in insulin/IGF-axis components that exceeded the basal expression levels in the organs of the female fetuses, which did not significantly respond to the IGF2 treatment.

A limitation of the study is the use of recombinant human IGF2 for the treatment of rat fetuses. As human IGF2 was shown previously to induce growth-promoting effects in rats because of the homology between human and rat IGF2 (ref. 18 ) and recombinant rat Igf 2 was not commercially available, we decided on the use of human IGF2. Fetal circulating levels of human IGF2 indicated the successful administration of IGF2 that reached fetal circulation. Resulting from the IGF2 administration, endogenous rat Igf2 decreased, but human IGF2 levels overwhelmed the normal, physiological Igf2 levels. Disruption of $H 19$ imprinting of the maternal allele in mice results in an about twofold increase in Igf2 mRNA expression (29). Loss of Igf $2 \mathrm{r}$ that, in normal conditions, mediates degradation of excess Igf 2 , results in a 2- to 2.7-fold increase in fetal circulating igf2 (ref. 36). Disruption of H19 imprinting in combination with the disruption of the maternally expressed $I g f 2 r$ increases fetal serum Igf2 levels up to 11fold (28). Direct effects of Igf2 overexpression in mouse chimeras made with transgenic embryonic stem cells increased Igf2 mRNA in fetal organs up to threefold (27). In our study, human IGF2 levels exceeded circulating endogenous Igf2 levels by more than 35-fold; however, one has to keep in mind that these levels are measured in the circulation and that human IGF2 levels in the organs may be lower.

Another limitation is that maternal corticosterone levels were not measured. Corticosterone is a marker for stress and, in mice, maternal corticosterone infusion at the beginning of pregnancy induces a reduction in placental igf 2 mRNA levels together with an increase in placental weight, but not in fetal weight on embryonic day 17.5 (ref. 43). However, we recorded weight and food consumption of the dams, which was not different from other time-matched pregnant dams that were not subjected to the procedure.

Besides the organs studied here, the effect of IGF2 on fetal adiposity would be an interesting aspect to study, as adipose tissue is responsive to IGF2 (ref. 44). However, rat fetuses are almost devoid of fat tissue of which accretion starts only after birth (45), and the study of IGF2 effects on offspring was not the focus of this study. In fact, the role of IGF2 in late pregnancy on fat accretion and on post-fetal growth in general would be certainly interesting for future studies.

Our data demonstrate that an increase in IGF2 during late pregnancy stimulates fetal organ growth of the digestive system, particularly in the male fetuses. Moreover, data highlight that male and female fetal growth is regulated differently, and may support the hypothesis that prenatal growth of male fetuses is more susceptible toward maternal nutritional insults than growth of female fetuses.

\section{STATEMENT OF FINANCIAL SUPPORT}

The study was supported by the Argentine National Agency for the Promotion of Science and Technology (ANPCyT) and the Scientific and Technology Project of Investigation to A.J. (PICT2015 0 0130) and V.W. (PICT2015 0750). V.W. was supported by an Ernst Mach fellowship of the Austrian Agency for International Cooperation in Education and Research (OEAD). A bilateral grant by the OEAD (AR1/2013 to U.H.) and the Argentine Science and Technology Ministery (MINCyT; AU1017 to V.W.) supported collaboration between the laboratories.

Disclosure: The authors declare no conflict of interest.

\section{REFERENCES}

1. Randhawa R, Cohen P. The role of the insulin-like growth factor system in prenatal growth. Mol Genet Metab 2005;86:84-90.

2. Savage MO, Burren CP, Rosenfeld RG. The continuum of growth hormone-IGF-I axis defects causing short stature: diagnostic and therapeutic challenges. Clin Endocrinol 2010;72:721-8.

3. Gicquel C, Le Bouc Y. Hormonal regulation of fetal growth. Horm Res 2006;65 (Suppl 3): 28-33.

4. Hill DJ. Relative abundance and molecular size of immunoreactive insulin-like growth factors I and II in human fetal tissues. Early Hum Dev 1990;21:49-58

5. Sacks DA. Determinants of fetal growth. Curr Diab Rep 2004;4:281-7.

6. Louvi A, Accili D, Efstratiadis A. Growth-promoting interaction of IGF-II with the insulin receptor during mouse embryonic development. Dev Biol 1997;189:33-48.

7. Smerieri A, Petraroli M, Ziveri MA, Volta C, Bernasconi S, Street ME. Effects of cord serum insulin, IGF-II, IGFBP-2, IL-6 and cortisol concentrations on human birth weight and length: pilot study. PLoS ONE 2011;6:e29562.

8. Harris LK, Crocker IP, Baker PN, Aplin JD, Westwood M. IGF2 actions on trophoblast in human placenta are regulated by the insulin-like growth factor 2 receptor, which can function as both a signaling and clearance receptor. Biol Reprod 2011;84:440-6.

9. Denley A, Cosgrove LJ, Booker GW, Wallace JC, Forbes BE. Molecular interactions of the IGF system. Cytokine Growth Factor Rev 2005;16: 421-39.

10. Smith AC, Choufani S, Ferreira JC, Weksberg R. Growth regulation, imprinted genes, and chromosome 11p15.5. Pediatr Res 2007;61: 43R-7RR.

11. Soejima H, Higashimoto K. Epigenetic and genetic alterations of the imprinting disorder Beckwith-Wiedemann syndrome and related disorders. J Hum Genet 2013;58:402-9.

12. Giudice LC, de Zegher F, Gargosky SE, et al. Insulin-like growth factors and their binding proteins in the term and preterm human fetus and neonate with normal and extremes of intrauterine growth. J Clin Endocrinol Metab 1995;80:1548-55.

13. Leger J, Oury JF, Noel M, et al. Growth factors and intrauterine growth retardation. I. Serum growth hormone, insulin-like growth factor (IGF)-I, IGF-II, and IGF binding protein 3 levels in normally grown and growthretarded human fetuses during the second half of gestation. Pediatr Res 1996;40:94-100.

14. St-Pierre J, Hivert MF, Perron P, et al. IGF2 DNA methylation is a modulator of newborn's fetal growth and development. Epigenetics 2012;7:1125-32.

15. Wallace JM, Milne JS, Aitken RP, et al. Undernutrition and stage of gestation influence fetal adipose tissue gene expression. J Mol Endocrinol 2015;54:263-75.

16. Su R, Wang C, Feng H, et al. Alteration in expression and methylation of igf2/h19 in placenta and umbilical cord blood are associated with macrosomia exposed to intrauterine hyperglycemia. PLoS ONE 2016;11: e0148399.

17. Bowers K, Laughon SK, Kiely M, Brite J, Chen Z, Zhang C. Gestational diabetes, pre-pregnancy obesity and pregnancy weight gain in relation to excess fetal growth: variations by race/ethnicity. Diabetologia 2013;56: $1263-71$. 


\section{IGF2 alters fetal growth sex-dependently $\quad$ Articles}

18. Calderari S, Gangnerau MN, Thibault M, et al. Defective IGF2 and IGF1R protein production in embryonic pancreas precedes beta cell mass anomaly in the Goto-Kakizaki rat model of type 2 diabetes. Diabetologia 2007;50:1463-71.

19. Martinez N, Kurtz M, Capobianco E, Higa R, White V, Jawerbaum A. PPARalpha agonists regulate lipid metabolism and nitric oxide production and prevent placental overgrowth in term placentas from diabetic rats. J Mol Endocrinol 2011;47:1-12.

20. Mazzucco MB, Higa R, Capobianco E, Kurtz M, Jawerbaum A, White V. Saturated fat-rich diet increases fetal lipids and modulates LPL and leptin receptor expression in rat placentas. J Endocrinol 2013;217:303-15.

21. White V, Jawerbaum A, Mazzucco MB, Gauster M, Desoye G, Hiden U. Diabetes-associated changes in the fetal insulin/insulin-like growth factor system are organ specific in rats. Pediatr Res 2015;77:48-55.

22. Silva D, Venihaki M, Guo WH, Lopez MF. Igf2 deficiency results in delayed lung development at the end of gestation. Endocrinology 2006;147:5584-91.

23. Ghanim M, Rossignol S, Delobel B, et al. Possible association between complex congenital heart defects and 11p15 hypomethylation in three patients with severe Silver-Russell syndrome. Am J Med Genet 2013;161A:572-7.

24. Geary MP, Pringle PJ, Rodeck CH, Kingdom JC, Hindmarsh PC. Sexual dimorphism in the growth hormone and insulin-like growth factor axis at birth. J Clin Endocrinol Metab 2003;88:3708-14.

25. Chaler EA, Meazza C, Guercio G, et al. Serum IGF-I and IGFBP-3 reference values from a chemiluminescent assay in normal children and adolescents of hispanic and italian origin: presence of sexual dimorphism in IGF-I values. J Pediatr Endocrinol Metab 2009;22:1127-35.

26. Weksberg R, Shuman C, Beckwith JB. Beckwith-Wiedemann syndrome. Eur J Hum Genet 2010;18:8-14.

27. Sun FL, Dean WL, Kelsey G, Allen ND, Reik W. Transactivation of Igf2 in a mouse model of Beckwith-Wiedemann syndrome. Nature 1997;389: 809-15.

28. Eggenschwiler J, Ludwig T, Fisher P, Leighton PA, Tilghman SM, Efstratiadis A. Mouse mutant embryos overexpressing IGF-II exhibit phenotypic features of the Beckwith-Wiedemann and Simpson-GolabiBehmel syndromes. Genes Dev 1997;11:3128-42.

29. Leighton PA, Ingram RS, Eggenschwiler J, Efstratiadis A, Tilghman SM. Disruption of imprinting caused by deletion of the H19 gene region in mice. Nature 1995;375:34-9.

30. Alberico S, Montico M, Barresi V, et al. The role of gestational diabetes, pre-pregnancy body mass index and gestational weight gain on the risk of newborn macrosomia: results from a prospective multicentre study. BMC Pregnancy Childbirth 2014;14:23.
31. Lingwood BE, Henry AM, d'Emden MC, et al. Determinants of body fat in infants of women with gestational diabetes mellitus differ with fetal sex. Diabetes Care 2011;34:2581-85.

32. Ricart W, Lopez J, Mozas J, et al. Maternal glucose tolerance status influences the risk of macrosomia in male but not in female fetuses. J Epidemiol Community Health 2009;63:64-8.

33. Kwong WY, Miller DJ, Ursell E, et al. Imprinted gene expression in the rat embryo-fetal axis is altered in response to periconceptional maternal low protein diet. Reproduction 2006;132:265-77.

34. Deierlein AL, Siega-Riz AM, Chantala K, Herring AH. The association between maternal glucose concentration and child BMI at age 3 years. Diabetes Care 2011;34:480-.

35. Kanaka-Gantenbein C. Fetal origins of adult diabetes. Ann N Y Acad Sci 2010;1205:99-105.

36. Lau MM, Stewart CE, Liu Z, Bhatt H, Rotwein P, Stewart CL. Loss of the imprinted IGF2/cation-independent mannose 6-phosphate receptor results in fetal overgrowth and perinatal lethality. Genes Dev 1994;8:2953-63.

37. Sakatani T, Kaneda A, Iacobuzio-Donahue CA, et al. Loss of imprinting of Igf2 alters intestinal maturation and tumorigenesis in mice. Science 2005;307:1976-8.

38. Petrik J, Pell JM, Arany E, et al. Overexpression of insulin-like growth factor-II in transgenic mice is associated with pancreatic islet cell hyperplasia. Endocrinology 1999;140:2353-63.

39. Angiolini E, Coan PM, Sandovici I, et al. Developmental adaptations to increased fetal nutrient demand in mouse genetic models of Igf2mediated overgrowth. FASEB J 2011;25:1737-45.

40. Mirghani H, Zayed R, Thomas L, Agarwal M. Gestational diabetes mellitus: fetal liver length measurements between 21 and 24 weeks' gestation. J Clin Ultrasound 2007;35:34-7.

41. Anderson NG, Notley E, Graham P, McEwing R. Reproducibility of sonographic assessment of fetal liver length in diabetic pregnancies. Ultrasound Obstet Gynecol 2008;31:529-34.

42. Cvitic S, Desoye G, Hiden U. Glucose, insulin, and oxygen interplay in placental hypervascularisation in diabetes mellitus. BioMed Res Int 2014;2014:145846.

43. Cuffe JS, O'Sullivan L, Simmons DG, Anderson ST, Moritz KM. Maternal corticosterone exposure in the mouse has sex-specific effects on placental growth and mRNA expression. Endocrinology 2012;153:5500-11.

44. Claycombe KJ, Uthus EO, Roemmich JN, Johnson LK, Johnson WT. Prenatal low-protein and postnatal high-fat diets induce rapid adipose tissue growth by inducing Igf2 expression in Sprague Dawley rat offspring. J Nutr 2013;143:1533-9.

45. Herrera E, Amusquivar E. Lipid metabolism in the fetus and the newborn. Diabetes Metab Res Rev 2000;16:202-10. 